\title{
Interactions between respiratory tract infections and atopy in the aetiology of asthma
}

\author{
P.G. Holt, P.D. Sly
}

Interactions between respiratory tract infections and atopy in the aetiology of asthma. P.G. Holt, P.D. Sly. C ERS Journals Ltd 2002.

ABSTRACT: The prevalence of asthma, in particular atopic asthma, has markedly increased in recent years. Accumulating evidence suggests that environmental factors associated with allergic sensitization and exposure to microbial stimuli during infancy and early childhood, are associated with these changes in prevalence. However, considerable controversy surrounds the role of microbial agents, as evidence has been presented for both positive and negative effects in this context.

The review below focuses upon interactions between immune competence during infancy, the development of T-helper (Th)1-polarized versus Th2-polarized memory against inhalant allergens, and susceptibility to virus infection. In particular, recent finding are highlighted which suggest that delayed postnatal maturation of Th1 function is associated with increased risk for early postnatal sensitization to inhalant allergens, and also with risk for viral bronchiolitis during infancy.

Variations in the kinetics of postnatal maturation of $T$-helper 1 function may in part be attributable to polymorphisms in the CD14 gene, which influence host responsiveness both to bacterial as well as viral stimuli.

Eur Respir J 2002; 19: 538-545.
TVW Telethon Institute for Child Health Research, Centre for Child Health Research, The University of Western Australia, Perth, Western Australia.

Correspondence: P.G. Holt, Division of Cell Biology, TVW Telethon Institute for Child Health Research, P.O. Box 855, West Perth, WA 6872, Australia.

Fax: 61894897707

E-mail: patrick@ichr.uwa.edu.au

Keywords: Asthma, atopy, bacterial stimuli, cytokines, viral infection

Received: March 222001

Accepted after revision May 82001
It is evident from a wide range of studies carried out in different geographical areas, that the prevalence of allergic diseases, and in particular atopic asthma, has increased markedly over the last 2-3 decades. Moreover, the increases become evident in successive birth cohorts during early childhood. It is also generally accepted that "diagnostic shift" is not a significant factor in these changes. Accordingly, given the timeframe over which the changes have occurred, the responsible factor(s) must be environmental, presumably interacting with one or more susceptibility genes.

The search for the relevant genetic and environmental factors continues, and a variety of potential candidates have been identified. Prominent amongst these are factors related to respiratory infections, particularly those occurring in childhood. Paradoxically, these infections have been invoked both as potential protective factors in relation to asthma/ allergy development, and as triggers of asthma exacerbations in atopic asthmatics. The mechanisms by which these effects may be mediated are incompletely understood; however, recent findings suggest some intriguing new possibilities, which are discussed in this review.

\section{T-cell immunity to inhalant allergens: the basis of variations in responder phenotype within the adult population}

The epithelial surface of the upper and lower respiratory tract are continuously exposed to an array of pathogenic and nonpathogenic airborne antigens, and the induction and local expression of local T-cell immunity must accordingly be tightly controlled, in order to avoid the pathological consequences of chronic T-cell-driven inflammation. While it is highly plausible that resistance to airborne pathogens is a direct function of the speed of mobilization and the intensity of expression of local innate and adaptive immune mechanisms in the lung, the converse situation appears more complex. In particular, it is not clear how the immune system avoids continually responding to airborne antigens,

Previous articles in this Series: No. 1: Pilette C, Ouadrhiri Y, Godding V, Vaerman J-P, Sibille Y. Lung mucosal immunity: immunoglobulin-A revisited. Eur Respir J 2001; 18: 571-588. No. 2: Lambrecht BN, Prins J-B, Hoogsteden HC. Lung dendritic cells and host immunity to infection. Eur Respir J 2001; 18: 692-704. No. 3: Moore BB, Moore TA, Toews GB. Role of T- and B-lymphocytes in pulmonary host defences. Eur Respir J 2001; 18: 846-856. No. 4: Message SD, Johnston SL. The immunology of virus infection in asthma. Eur Respir J 2001; 18: 1013-1025. No. 5: Crameri R, Blaser K. Allergy and immunity to fungal infections and colonization. Eur Respir J 2002; 19: 151-157. No. 6: De Rose V. Mechanisms and markers of airway inflammation in cystic fibrosis. Eur Respir J 2002; 19: 333-340. 
such as pollens, which are intrinsically nonpathogenic, whilst being both highly immunogenic and ubiquitous in the natural environment.

The classical explanation for this discrimination has envisaged the mucosal immune system mounting localized secretory immunoglobulin (Ig)-A responses against such antigens. This IgA "blanket" has been perceived to function as a protective exclusion barrier to minimize the penetration of inert antigens below epithelia, thus preventing effective systemic sensitization of the immune system. However, the results of studies arising from the introduction of T-cell cloning technology into this field have necessitated a radical revision of these ideas. Notably, it is now clear that active T-cell immunity to common nonpathogenic airborne antigens is essentially universal within the adult human population, and that qualitative aspects of these immune responses determine relevant clinical outcomes (if any).

Thus, the majority of individuals contain populations of recirculating memory $\mathrm{T}$-cells in their peripheral blood which recognize pollen antigens (and many other such proteins present in indoor and outdoor dusts), and in doing so are triggered to release low levels of cytokines such as interferon (IFN)- $\gamma$, which are characteristic of the T-helper (Th) 1 pattern of T-cell immunity [1, 2]. Such subjects produce only low levels of allergen-specific IgG antibodies, and manifest no clinical symptoms upon exposure. In contrast, a minority of subjects contain T-memory cells, which respond to the same antigens via release of Th2-associated cytokines such as interleukin (IL)-4, IL-5 and IL-13 [1, 2], often in conjunction with IFN- $\gamma$ (i.e. Th0-like; $[3,4]$ ).

The dichotomous cytokine secretion patterns were originally defined in the murine system [5], and the extrapolation of this $\mathrm{Th} 1 / \mathrm{Th} 2$ paradigm to the human system is not universally accepted. In particular, it has been pointed out that the hallmark of Th1 immunity in the mouse is delayed type hypersensitivity (DTH), and yet there is no evidence of allergenspecific DTH in nonatopics who ostensibly contain Th1-polarized allergen-specific Th memory cells [6]. In relation to this debate, the authors have recently employed alternative measures of T-cell immunity to analyse qualitative aspects of Th memory to allergens in humans. The authors have demonstrated [7] that during the initial phase of antigen-specific reactivation, Th memory cells exhibit characteristic patterns of expression of transcription factors (TF), which mirror those seen during cytokine-driven polarization of naive cells down the Th1 or Th2 differentiation pathways. Notably, Th2 differentiation is associated with upregulation of expression of the TF GATA-3, while Th1 differentiation is associated with a reciprocal pattern of active downregulation of the GATA-3 gene. An identical dichotomy in GATA-3 expression patterns is seen when peripheral blood CD4+ T-cells from atopics and nonatopics are stimulated in vitro with common inhalant allergens, such as house dust mite [7], providing independent confirmation of the applicability of the Th1/Th2 paradigm to humans.

In relation to the aetiology of atopic asthma, the central issue is then: how are these dichotomous $\mathrm{Th}$ memory patterns programmed?

\section{Allergen-specific T-helper memory programming in childhood}

A variety of evidence indicates that initial priming of the naive immune system against inhalant allergens occurs during early life, in many cases during late gestation. This conclusion is based on a series of studies from independent laboratories [8-12] demonstrating the presence of cells in cord blood mononuclear (CBMC) specimens, which proliferate in response to allergens. Additionally, a recent study from the authors' group involving deoxyribonucleic acid genotyping of $\mathrm{T}$-cell clones derived from such cultures has confirmed the foetal origin of the responder cells [13].

It is not clear from these studies whether initial Th-cell priming occurs via contact with native allergen, which is transported across the placenta, or via stimulation with cross-reacting antigens. However, tracking these responses postnatally in a series of cross-sectional and prospective studies from several labs (e.g. [14-16]) has revealed a characteristic pattern of "response maturation", which segregates atopics from nonatopics. A clear example is demonstrated in recent results from the authors' laboratory. Firstly, these show that initial low-level responses in CBMC are dominated by Th2 cytokines [13], but are subsequently modified during infancy and early childhood. Thus, Th2 reactivity is steadily boosted in children who progress to early expression of atopy symptoms [14] and/or skin-prick test positivity to inhalants [17, 18]; whereas, these responses are diverted ("immune deviated") towards a Th1-like pattern in the nonatopics. This Th memory generation process in many individuals appears to be complete by the end of the preschool or early school years, potentially locking individuals into lifelong patterns of allergen responsiveness. However, as discussed later, this memory generation process is not the sole determinant of clinical responder phenotype, in particular in relation to asthma, as only a subset of children sensitized to inhalant allergens go on to develop persistent wheeze [19].

\section{Genetic versus environmental determinants of allergic sensitization: the significance of microbial exposure in early life}

The genetic basis for susceptibility to allergic respiratory disease is the subject of intensive research internationally. It is acknowledged that a variety of genes are likely to be involved in this highly complex disease. However, some key elements in the process can be deduced from studies focusing on issues relevant to $\mathrm{Th} 1 / \mathrm{Th} 2$ responsiveness in atopics and nonatopics.

Literature from the $1970 \mathrm{~s}$, relating primarily to expression of severe atopic disease (especially atopic dermatitis) in childhood, contains a range of independent reports suggesting that various aspects of 
adaptive immune function in affected subjects was deficient, relative to healthy aged-matched controls. More recently, the authors' laboratory has sought to extend these findings to allergic disease in general. The key findings, based upon quantitative T-cell cloning studies and cytokine analyses on extensive panels of isolated clones, indicate that an important element of genetic susceptibility to atopy involves delayed postnatal maturation of Th1 function [20]. The present authors showed that the capacity of CD4+ Th-cells from infants at high risk (HR) of atopy to produce both Th1 and Th2 cytokines was reduced relative to their low risk (LR) counterparts; however, the reduction in IFN- $\gamma$ was greatest, resulting in a relative Th2 "skewing" of responsiveness in the HR children. These findings have since been extended to $\mathrm{CBMC}$ in confirmatory studies from a range of independent laboratories [21-26].

The present interpretation of these findings [27], based on the literature relating to the immunology of pregnancy, is that the process involving the normal transition of adaptive immune function from the foetal Th2-polarized state, to the more balanced but Th1-dominant state characteristic of the mature immune system, progresses more slowly in HR than in LR children. Furthermore, it can be hypothesized that as a result of this delay, HR children will be at heightened risk of occasional "failures" in the immune deviation process which underlies the repolarization of neonatal Th2-skewed responses to allergens towards the Th1 pattern characteristic of nonatopics [27].

The precise kinetics and nature of the mechanism(s) underlying the postnatal maturation of Th1 function are not completely understood, but recent findings in several areas are shedding fresh light on the process. Firstly, experimental studies in mouse models have demonstrated the important role of promoter methylation in silencing of the IFN- $\gamma$ gene in Th2 cells [27], and recent studies from the authors' laboratory (P.G. Holt, TVW Telethon Institute for Child Health Research, Perth, Western Australia, personal communication) suggest that hyperactivity of a comparable mechanism in human foetal naive CD4+ T-cells may be responsible for their reduced capacity to transcribe the IFN- $\gamma$ gene, relative to their adult CD4+ counterparts. Secondly, other previous studies from animal models [28] indicate that postnatal maturation of immune function in mammals is driven by contact with microbial stimuli not usually encountered during foetal life, and that an important part of this stimulation is directed selectively towards Th1 functions [29]. Accordingly, the authors have proposed that one of the factors underlying the differences in kinetics of the Th1 maturational process may involve genetically determined variations in capacity to respond to these microbial stimuli in early life [26]. One example of this may underlie the findings of Shirakawa et al. [30], which indicate that failure to generate long-term Th1-polarized memory in response to bacille Calmette-Guérin immunization during infancy, is associated with heightened risk for subsequent development of atopy and asthma.

A second example of a pathway, which is likely to be of major importance in this context, involves the CD14 gene encoding the high affinity receptor for bacterial lipopolysaccharide (LPS). It is highly likely that LPS, by virtue of its capacity to stimulate Th1-trophic IL-12 production via soluble CD14 dependent mechanisms, plays a key role in postnatal upregulation of Th1 function, and the authors have hypothesized that normal gastrointestinal bacterial flora may play a key role in this process [31]. Recent findings from MATRICARDi et al. [32] suggest that gastrointestinal pathogens potentially exert similar effects.

The present authors have additionally collaborated with BALDINI et al. [33] in identification of a polymorphism in the CD14 gene, which is associated with reduced levels of soluble CD14 in serum, decreased Th1 function, and increased intensity of atopic sensitization. This polymorphism may have additional implications, given the recent report demonstrating a key role for CD14 in mediating the innate immune response to respiratory syncytial virus (RSV) [34]. It is feasible that further polymorphisms in genes related to the recognition of microbial (particularly viral) stimuli await discovery.

In this regard, it is also pertinent to note the recent reports suggesting that exposure to LPS in airborne dusts during childhood appears to be inversely related to sensitization to inhalant allergens $[35,36]$. A potential explanation for these findings involves the known stimulatory effects of LPS on dendritic cell (DC) populations in the airway mucosa (discussed later).

\section{The apparent dualistic effects of respiratory tract infection on asthma and allergy}

It is clear from studies in school children that respiratory viral infections are potent triggers of asthma exacerbations, in particular in atopic asthmatics [37]. It is also evident that lower respiratory tract infections during infancy, in particular those which occur at a level of severity sufficient to trigger wheeze, are associated with increased risk for subsequent development of persistent airway hyperresponsiveness (AHR; [38, 39]). In relation to acute exacerbations, while the precise mechanisms remain to be defined, it is likely that the onset of wheeze is at least partially the result of the summation of airway tissue damage resulting from the host response to the infection, together with that stemming from ongoing Th2-mediated immuno-inflammatory responses to inhalant allergens.

One factor which contributes significantly to the confusion surrounding the relationship between respiratory infections and childhood asthma is the lack of clear phenotypic descriptions of asthma in children. The old adage that "all that wheezes is not asthma" almost certainly applies here. At least three distinct wheezing syndromes can be recognized in children, each of which have different risk factors and may have different prognostic implications. These syndromes have been called by various names, but a consensus appears to be forming around the terms 
"transient infantile wheeze", "viral-associated wheeze" and "atopic asthma". Whether these three conditions are different parts of a single disease spectrum or represent different diseases remains to be established.

Wheezing in the first year of life is common, with $30 \%$ of infants having at least one wheezy episode in some series [40]. Transient infantile wheeze describes a condition where the infant wheezes during the first year or two, but not later. This syndrome appears to be more common in infants born to mothers who smoke and to young mothers and is not associated with an increased prevalence of atopy later in life. Viral-associated wheezing is very common in young children in the preschool and early school years. Many studies have shown an increased prevalence of wheezing during childhood following RSV infection in infancy, but none show an increase in the prevalence of atopy in these children. Recently, STEIN et al. [41] have demonstrated that RSV infection in early life is a risk factor for wheezing up to 6 yrs of age, but that this risk has gone by 13 yrs. Again, the children in that study who had RSV infection in early life did not have an increased prevalence of atopy at 13 yrs. Viralassociated wheeze may be responsible for the majority of wheezing episodes in young children and may represent the majority of doctor-diagnosed asthma occurring in this age group. If this is the same syndrome as that described by STEIN et al. [41], it may also be responsible for the widely-held view that many children "grow out of" their asthma.

In relation to the longer term effects of infections occurring in infancy, it has been hypothesized that severe airway inflammation during this critical phase of rapid lung growth can initiate phenotypic changes in airway tissues, which are amplified during subsequent growth and differentiation, resulting eventually in expression of AHR [38, 39]. It has also been hypothesized that certain viruses, in particular RSV, have the potential to selectively stimulate "bystander" Th2 responses $[42,43]$, and thus amplify the development of Th2-polarized immunological memory against inhalant allergens. However, these effects may be transient, given the results of a recent longterm follow-up study, which failed to detect a link between early RSV infection and long-term expression of atopy [41].

Conversely, it has also been suggested that other respiratory infections, either due to the time at which they occur or to their particular localization and/or level of severity, may have opposite long-term effects, and instead protect against allergic sensitization and/ or asthma development [44-47]. For example, American children, who develop more than one nonwheezing lower respiratory tract infection before the age of 3 yrs, display a marked reduction in atopy prevalence [48], and Estonian schoolchildren display very low allergy prevalence, but experience more prolonged and intense respiratory infections than Western European children in whom allergy is frequent [49]. One plausible mechanism for such effects involves infection-mediated stimulation of airway mucosal DC populations, which regulate the Th1/Th2 balance in immune responses to inhaled antigens [50]. These DCs rely absolutely upon the receipt of appropriate inflammatory cytokine signals, and/or stimulation from microbial products, such as LPS or viral nucleic acid, in order to upregulate their production of IL-12, which they utilize in driving Th-cell responses down the Th1 differentiation pathway [51]. In immunocompetent adult experimental animals, airway DC networks are highly responsive to viral/bacterial stimulation [52], but this and related T-cell regulatory functions are attenuated in infant animals $[53,54]$ and require prolonged stimulation to promote functional maturation. A recent study suggests that human airway DC populations are normally at a similar low baseline activity state during infancy, and they may upregulate to a significant degree in response to severe infection [55]. Furthermore, this may represent a mechanism by which certain infections in early life could help to tip the balance towards development of Th1 as opposed to Th2 immunity to ubiquitous aeroallergens. One prediction of such a model would be that such potentially "protective" infections may be restricted to those which are localized to the mucosae of the upper airways, which represent the principal sites for the deposition of inhaled allergens.

At present, these conflicting notions appear difficult to reconcile. However, a number of authors have suggested that the nature of the relationship(s) between infection and asthma/atopy in early life may be more complex than previously considered. For example, it has been suggested that RSV-induced wheeze in infancy may be a marker for pre-existing atopic predisposition, as opposed to a stimulant for Th2 differentiation [50]. Recent results from studies relating to host responses to RSV in early life are beginning to clarify this issue, and these are discussed in the conclusion of this review.

\section{Interactions between infection and allergic sensitization in asthma and childhood: dissection of cause/effect relationships}

As noted earlier, a key issue that requires further clarification concerns the nature of the short- and long-term sequelae of lower respiratory tract infections, in particular the nature of the cause/effect interrelationships between atopy/asthma.

The scheme mentioned later and detailed in figure 1 illustrates the potential causal pathways in the aetiology of asthma, representing the authors' current view of how a significant proportion of the contentious literature in this area can be reconciled. The following principal observations underpin the atopy component of this scheme. 1) Allergen-specific Th-cell priming occurs in the perinatal period [8-13], and these early immune responses become compartmentalized into Th1- or Th2-polarized memory during the preschool years [14-18]. 2) The symptomatology associated with the sensitization to inhalants during childhood does not usually progress beyond intermittent wheeze, and severe long-term sequelae appear restricted to a subset of atopics [19] manifesting high levels of Th2-mediated inflammation [56-58] and subsequent airway remodelling [57, 58]. 3) The excessive airway inflammation in this subset implies 


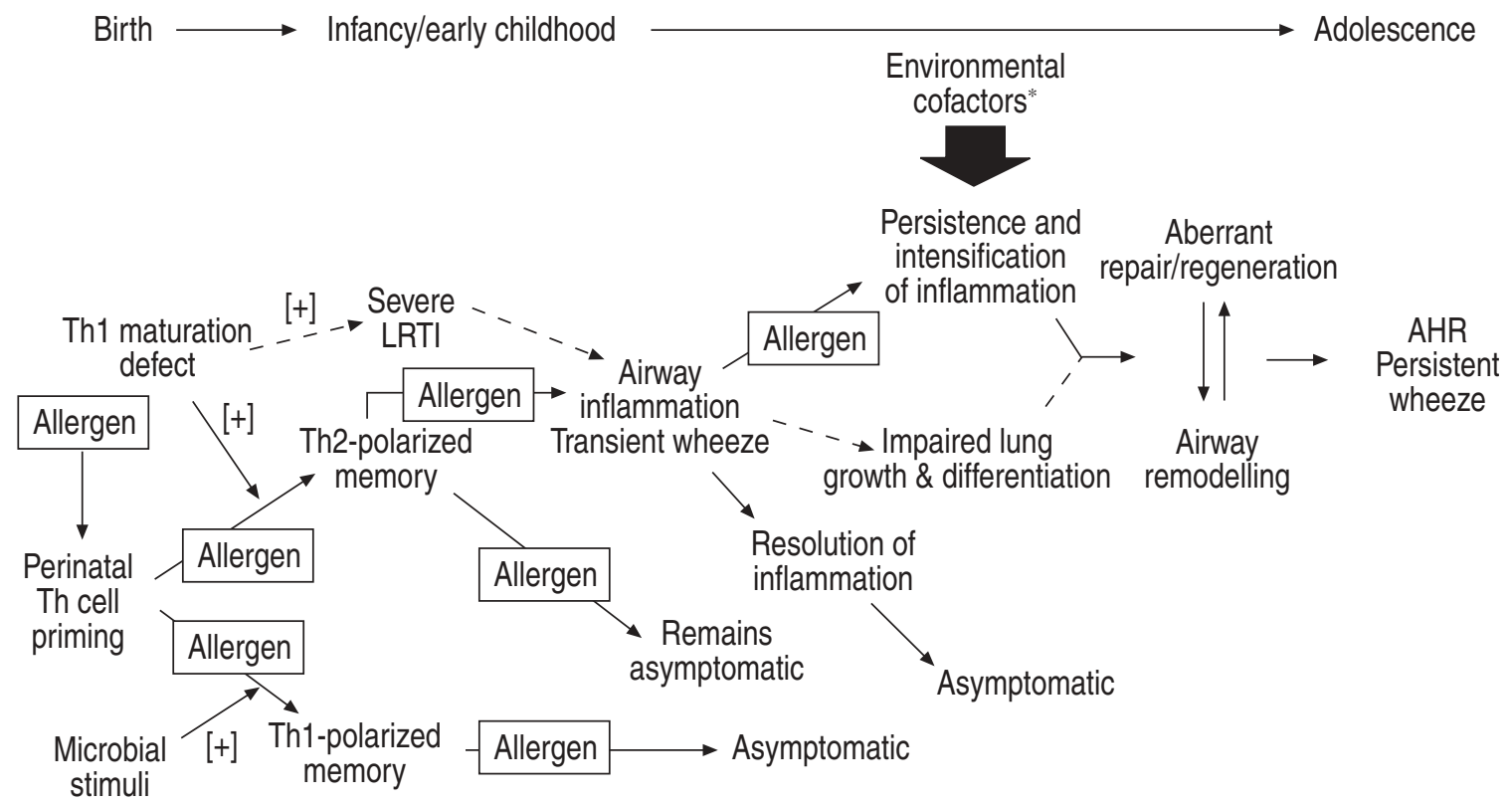

Fig. 1.-A multistage model for interactions between infections and atopy in the aetiology of asthma. LRTI: lower respiratory tract infection; AHR: airway hyperresponsiveness; Th: T-helper cell; $[+]$ : stimulates or predisposes to. *: includes virus infections, environmental irritants, allergen load/type, etc. See text for background references relating to the construction of these pathways.

the existence of additional host and environmental cofactors which are "pro-inflammatory"; these may include genetic factors associated with dysregulation of immunological control mechanisms within the airway mucosa, and a series of environmental factors [58]. 4) The earlier that Th2-polarized memory against inhalant allergens develops, the more severe are the long-term consequences in relation to $\operatorname{AHR}[59,60]$, implying that repeated cycles of airway inflammation during rapid lung growth may establish some form of "matrix" for development of subsequent changes associated with airway remodelling. 5) Genetic risk for atopy is associated with sluggish postnatal maturation of adaptive immune function, in particular, Th1 function [20, 27].

With respect to the infection component in the scheme, the relevant recent observations are as follows: 1) genetic risk for atopy has been reported to be associated with increased susceptibility to severe RSV infection and bronchiolitis [61]; atopy in children has also been linked to increased susceptibility to measles-mumps-rubella [62] as well as to frequent upper respiratory tract infections [63]; 2) IFN- $\gamma$ responses in peripheral blood mononuclear cells are attenuated during acute RSV infection in children who develop bronchiolitis [59-69], suggesting that downregulated Th1 function may be associated with pathogenesis; 3) susceptibility to development of acute RSV bronchiolitis during infancy is associated with decreased levels of IL-12 in cord blood relative to subjects who do not develop bronchiolitis [70], suggesting a pre-existing deficiency in Th1 function in this group; 4) nonatopic wheezing children, in whom the principal stimulus for wheeze is viral infection per se, also have manifest reduced IFN- $\gamma$ responses [71]; and 5) a recent study by the authors' group on a prospective cohort of infants followed to 18 months indicated that the development of T-cell memory to RSV (as a surrogate marker for RSV infection) during the observation period was inversely related to kinetics of postnatal maturation of IFN- $\gamma$ responses [72].

Collectively, these findings suggest that a comparable genetic defect, associated with delayed postnatal maturation of Th1 function, may underlie susceptibility both to atopic sensitization and the development of severe respiratory viral infections, as well as their spread to the lower airways. Such infections trigger wheeze in the short term, and in a significant proportion of cases they may be of sufficient severity to subtly impair ongoing lung growth and differentiation, thus initiating changes, which subsequently synergize with those resulting from later episodes of airway inflammation, triggered by other stimuli such as allergens.

The present scheme cannot account for all of the potential roles of viral infections in the aetiology of asthma, in particular those associated with adultonset nonatopic asthma, although the findings of LEECH et al. [71] may be relevant to this issue. However, the scheme does provide a rational framework for future systematic research into this complex problem.

\section{References}

1. Wierenga EA, Snoek M, de Groot C, et al. Evidence for compartmentalization of functional subsets of $\mathrm{CD} 2+\mathrm{T}$ lymphocytes in atopic patients. J Immunol 1990; 144: 4651-4656.

2. Romagnani S. Human TH1 and TH2 subsets: doubt no more. Immunol Today 1991; 12: 256-257. 
3. Byron KA, O'Brien RM, Varigos GA, Wootton AM. Dermatophagoides pteronyssinus II-induced interleukin- 4 and interferon- $\gamma$ expression by freshly isolated lymphocytes of atopic individuals. Clin Exp Allergy 1994; 24: 878-883.

4. Essayan DM, Han W-F, Xiao H-Q, Kleine-Tebbe J, Huang S-K. Clonal diversity of IL-4 and IL-13 expression in human allergen-specific $\mathrm{T}$ lymphocytes. J Allergy Clin Immunol 1996; 98: 1035-1044.

5. Mosmann TR, Coffman RL. TH1 and TH2 cells: different patterns of lymphokine secretion lead to different functional properties. Annu Rev Immunol 1989; 7: 145-173.

6. Borish L, Rosenwasser L. Th1/Th2 lymphocytes: doubt some more. J Allergy Clin Immunol 1997; 99: $161-164$.

7. Macaubas C, Holt PG. Regulation of cytokine production in $\mathrm{T}$-cell responses to inhalant allergen: GATA-3 expression distinguishes between Th1 and Th2-polarised immunity. Int Arch Allergy Immunol 2001; 124: 176-179.

8. Kondo N, Kobayashi Y, Shinoda S, et al. Cord blood lymphocyte responses to food antigens for the prediction of allergic disorders. Arch Dis Child 1992; 67: 1003-1007.

9. Piccinni M-P, Mecacci F, Sampognaro S, et al. Aeroallergen sensitization can occur during fetal life. Int Arch Allergy Immunol 1993; 102: 301-303.

10. Piastra M, Stabile A, Fioravanti G, Castagnola M, Pani G, Ria F. Cord blood mononuclear cell responsiveness to beta-lactoglobulin: T-cell activity in "atopy-prone" and "non-atopy-prone" newborns. Int Arch Allergy Immunol 1994; 104: 358-365.

11. Warner JA, Jones AC, Miles EA, Colwell BM, Warner JO. Maternofetal interaction and allergy. Allergy 1996; 51: 447-451.

12. Holt PG, $\mathrm{O}^{\prime}$ Keeffe PO, Holt BJ, et al. T-cell "priming" against environmental allergens in human neonates: sequential deletion of food antigen specificities during infancy with concomitant expansion of responses to ubiquitous inhalant allergens. Ped Allergy Immunol 1995; 6: 85-90.

13. Prescott SL, Macaubas $\mathrm{C}$, Holt BJ, et al. Transplacental priming of the human immune system to environmental allergens: universal skewing of initial T-cell responses towards the Th- 2 cytokine profile. J Immunol 1998; 160: 4730-4737.

14. Prescott SL, Macaubas C, Smallacombe T, Holt BJ, Sly PD, Holt PG. Development of allergen-specific T-cell memory in atopic and normal children. Lancet 1999; 353: 196-200.

15. Piccinni M-P, Beloni L, Giannarini L, et al. Abnormal production of $\mathrm{T}$ helper 2 cytokines interleukin- 4 and interleukin- 5 by $\mathrm{T}$ cells from newborns with atopic parents. Eur J Immunol 1996; 26: 2293-2298.

16. Miles EA, Warner JA, Jones AC, Colwell BM, Bryant TN, Warner JO. Peripheral blood mononuclear cell proliferative responses in the first year of life in babies born to allergic parents. Clin Exp Allergy 1996; 26: 780-788.

17. Yabuhara A, Macaubas C, Prescott SL, et al. Th-2polarized immunological memory to inhalant allergens in atopics is established during infancy and early childhood. Clin Exp Allergy 1997; 27: 1261-1269.

18. Macaubas C, Sly PD, Burton P, et al. Regulation of Th-cell responses to inhalant allergen during early childhood. Clin Exp Allergy 1999; 29: 1223-1231.
19. Woolcock AJ, Peat JK, Trevillion LM. Is the increase in asthma prevalence linked to increase in allergen load? Allergy 1995; 50: 935-940.

20. Holt PG, Clough JB, Holt BJ, et al. Genetic 'risk' for atopy is associated with delayed postnatal maturation of T-cell competence. Clin Exp Allergy 1992; 22: 10931099.

21. Rinas $\mathrm{U}$, Horneff $\mathrm{G}$, Wahn V. Interferon- $\gamma$ production by cord-blood mononuclear cells is reduced in newborns with a family history of atopic disease and is independent from cord blood IgE-levels. Pediatr Allergy Immunol 1993; 4: 60-64.

22. Tang MLK, Kemp AS, Thorburn J, Hill DJ. Reduced interferon- $\gamma$ secretion in neonates and subsequent atopy. Lancet 1994; 344: 983-986.

23. Liao SY, Liao TN, Chiang BL, et al. Decreased production of IFN $\gamma$ and increased production of IL-6 by cord blood mononuclear cells of newborns with a high risk of allergy. Clin Exp Allergy 1996; 26: $397-$ 405 .

24. Martinez FD, Stern DA, Wright AL, Holberg CJ, Taussig LM, Halonen M. Association of interleukin-2 and interferon- $\gamma$ production by blood mononuclear cells in infancy with parental allergy skin tests and with subsequent development of atopy. J Allergy Clin Immunol 1995; 96: 652-660.

25. Warner JA, Miles EA, Jones AC, Quint DJ, Colwell $\mathrm{BM}$, Warner JO. Is deficiency of interferon gamma production by allergen triggered cord blood cells a predictor of atopic eczema? Clin Exp Allergy 1994; 24: 423-430.

26. Williams TJ, Jones CA, Miles EA, Warner JO, Warner JA. Fetal and neonatal IL-13 production during pregnancy and at birth and subsequent development of atopic symptoms. $J$ Allergy Clin Immunol 2000; 105: 951-959.

27. Holt PG, Macaubas C. Development of long term tolerance versus sensitisation to environmental allergens during the perinatal period. Curr Opin Immunol 1997; 9: 782-787.

28. Holt PG. Environmental factors and primary T-cell sensitisation to inhalant allergens in infancy: reappraisal of the role of infections and air pollution. Pediatr Allergy Immunol 1995; 6: 1-10.

29. Sudo N, Sawamura S-A, Tanaka K, Aiba Y, Kubo C, Koga Y. The requirement of intestinal bacterial flora for the development of an IgE production system fully susceptible to oral tolerance induction. J Immunol 1997; 159: 1739-1745.

30. Shirakawa T, Enomoto T, Shimazu S, Hopkin JM. Inverse association between tuberculin responses and atopic disorder. Science 1997; 275: 77-79.

31. Holt PG, Sly PD, Bjorksten B. Atopic versus infectious diseases in childhood: a question of balance? Ped Allergy Immunol 1997; 8: 53-58.

32. Matricardi PM, Rosmini F, Riondino S, et al. Exposure of foodborne and orofecal microbes versus airborne viruses in relation to atopy and allergic asthma: epidemiological study. BMJ 2000; 320: 412 417.

33. Baldini $M$, Lohman IC, Halonen $M$, Erickson RP, Holt PG, Martinez FD. A polymorphism in the 5 '-flanking region of the CD14 gene is associated with circulating soluble CD14 levels with total serum IgE. Am J Respir Cell Mol Biol 1999; 20: 976-983.

34. Kurt-Jones EA, Popova L, Kwinn L, et al. Pattern recognition receptors TLR4 and CD14 mediate 
response to respiratory syncytial virus. Nature Immunol 2000; 1: 398-401.

35. Von Ehrenstein OS, Von Mutius E, Illi S, Baumann L, Von Kries R. Reduced risk of hay fever and asthma amongst children of farmers. Clin Exp Allergy 2000; 30: 187-193.

36. Gereda JE, Leung DYM, Thatayatikom A, et al. Relation between house-dust endotoxin exposure, type 1 T-cell development, and allergen sensitisation in infants at high risk of asthma. Lancet 2000; 355: 1680 1683.

37. Johnston SL, Pattemore PK, Sanderson G, et al. The relationship between upper respiratory infections and hospital admissions for asthma: a time-trend analysis. Am J Respir Crit Care Med 1996; 154: 654-660.

38. Martinez FD, Wright AL, Taussig LM, et al. Asthma and wheezing in the first six years of life. $N$ Engl $\mathrm{J} \mathrm{Med}$ 1995; 332: 133-138.

39. Welliver RC, Duffy L. The relationship of RSVspecific immunoglobulin $\mathrm{E}$ antibody responses in infancy, recurrent wheezing, and pulmonary function at age 7-8 years. Pediatr Pulmonol 1993; 15: 19-27.

40. Landau LI. Asthma: Prognosis. In: Taussig LM, Landau LI, LeSouef PN, Morgan WJ, Martinez FD, Sly PD, eds. Pediatric Respiratory Medicine. St Louis, Mosby, 1999; pp. 935-938.

41. Stein RT, Sherrill D, Morgan WJ, et al. Respiratory syncytial virus in early life and risk of wheeze and allergy by age 13 years. Lancet 1999; 353: 541-545.

42. Sparer TE, Matthews S, Hussell T, et al. Eliminating a region of respiratory syncytial virus attachment protein allows induction of protective immunity without vaccine-enhanced lung eosinophilia. $J$ Exp Med 1998; 187: 1921-1926.

43. Sigurs N, Bjarnason R, Sigurbergsson F, Kjellman B, Bjorksten B. Asthma and immunoglobulin E antibodies after respiratory syncytial virus bronchiolitis: a prospective cohort study with matched controls. Pediatrics 1995; 95: 500-505.

44. Gerrard JW, Geddes CA, Reggin PL, Gerrard CD, Horne S. Serum IgE levels in white and Metis communities in Saskatchewan. Ann Allergy 1976; 37 : 91-100.

45. Strachan DP. Hay fever, hygiene, and household size. BMJ 1989; 299: 1259-1260.

46. Martinez FD. Role of viral infections in the inception of asthma and allergies during childhood: could they be protective? Thorax 1994; 49: 1189-1191.

47. Holt PG. Infections and the development of allergy. Toxicol Lett 1996; 86: 205-210.

48. Martinez FD, Stern DA, Wright AL, Taussig LM, Halonen M, Associates GHM. Association of nonwheezing lower respiratory tract illnesses in early life with persistently diminished serum IgE levels. Thorax 1995; 50: 1067-1072.

49. Braback L, Breborowicz A, Dreborg S, Knutsson A, Pieklik H, Bjorksten B. Atopic sensitisation and respiratory symptoms among Polish and Swedish school children. Clin Exp Allergy 1994; 24: 826-835.

50. Holt PG, Stumbles PA. Regulation of immunological homeostasis in peripheral tissues by dendritic cells: the respiratory tract as a paradigm. $J$ Allergy Clin Immunol 2000; 105: 421-429.

51. Stumbles PA, Thomas JA, Pimm CL, et al. Resting respiratory tract dendritic cells preferentially stimulate Th2 responses and require obligatory cytokine signals for induction of Th1 immunity. $J$ Exp Med 1998; 188: 2019-2031.

52. McWilliam AS, Napoli S, Marsh AM, et al. Dendritic cells are recruited into the airway epithelium during the inflammatory response to a broad spectrum of stimuli. J Exp Med 1996; 184: 2429-2432.

53. Nelson DJ, McMenamin C, McWilliam AS, Brenan M, Holt PG. Development of the airway intraepithelial dendritic cell network in the rat from class II MHC (Ia) negative precursors: differential regulation of Ia expression at different levels of the respiratory tract. $J$ Exp Med 1994; 179: 203-212.

54. Nelson DJ, Holt PG. Defective regional immunity in the respiratory tract of neonates is attributable to hyporesponsiveness of local dendritic cells to activation signals. J Immunol 1995; 155: 3517-3524.

55. Tschernig T, Debertin AS, Paulsen F, Kleemann WJ, Pabst R. Dendritic cells in the mucosa of the human trachea are not regularly found in the first year of life. Thorax 2001; 56: 427-431.

56. Corrigan CJ, Kay AB. T-cells and eosinophils in the pathogenesis of asthma. Immunol Today 1992; 13: 501-507.

57. Holgate S. The inflammation-repair cycle in asthma: the pivotal role of the airway epithelium. Clin Exp Allergy 1998; 28: Suppl. 5, 97-103.

58. Holt PG, Macaubas C, Stumbles PA, Sly PD. The role of allergy in the development of asthma. Nature 1999; 402: B12-B17.

59. Peat JK, Salome CM, Woolcock AJ. Longitudinal changes in atopy during a 4-year period: Relation to bronchial hyperresponsiveness and respiratory symptoms in a population sample of Australian schoolchildren. J Allergy Clin Immunol 1990; 85: 6574.

60. Sherrill D, Stein R, Kurzius-Spencer M, Martinez F. Early senstization to allergens and development of respiratory symptoms. Clin Exp Allergy 1999; 29: 905911.

61. Trefny P, Stricker T, Baerlocher C, Sennhauser FH. Family history of atopy and clinical course of RSV infection in ambulatory and hospitalized infants. Pediatr Pulmonol 2000; 30: 302-306.

62. Paunio M, Heinonen O, Virtanen M, Leinikki P, Patja A, Peltola H. Measles history and atopic diseases: a population-based cross-sectional study. JAMA 2000; 283: 343-346.

63. Oddy WH, de Klerk N, Sly PD, Holt PG. Antecedents of childhood asthma: respiratory infections, atopy and breast-feeding have independent and multiplicative effects. Eur Respir $J 2002$ (in press).

64. Renzi PM, Turgeon JP, Yang JP, et al. Cellular immunity is activated and a Th-2 response is associated with early wheezing in infants after bronchiolitis. J Pediatr 1997; 130: 584-593.

65. Roman M, Calhoun WJ, Hinton KL, et al. Respiratory syncytial virus infection in infants is associated with predominant Th-2-like response. Am J Respir Crit Care Med 1997; 156: 190-195.

66. Bont L, Heijnen CJ, Kavelaars A, et al. Peripheral blood cytokine responses and disease severity in respiratory syncytial virus bronchiolitis. Eur Respir $J$ 1999; 14: 144-149.

67. Aberle JH, Aberle SW, Dworzak MN, et al. Reduced interferon- $\gamma$ expression in peripheral blood mononuclear cells of infants with severe respiratory 
syncytial virus disease. Am J Respir Crit Care Med 1999; 160: 1263-1268.

68. Renzi PM, Turgeon JP, Marcotte JE, et al. Reduced interferon- $\gamma$ production in infants with bronchiolitis and asthma. Am J Respir Crit Care Med 1999; 159: 1417-1422.

69. Bendelja K, Gagro A, Bace A, et al. Predominant type-2 response in infants with respiratory syncytial virus (RSV) infection demonstrated by cytokine flow cytometry. Clin Exp Immunol 2000; 121: 332-338.

70. Blanco-Quiros A, Gonzalez H, Arranz E, Lapena S.
Decreased interleukin-12 levels in umbilical cord blood in children who developed acute bronchiolitis. Pediatr Pulmonol 1999; 28: 175-180.

71. Leech SC, Price JF, Holmes BJ, Kemeny BJ. Nonatopic wheezy children have reduced interferongamma. Allergy 2000; 55: 74-78.

72. Rowe J, Macaubas C, Monger T, et al. Heterogeneity in DTaP vaccine-specific cellular immunity during infancy: relationship to variations in the kinetics of postnatal maturation of systemic Th1 function. $J$ Infect Dis 2001; 184: 80-88. 